\title{
Differential Effects of Thiazolidinediones and Dipeptidyl Peptidase-4 Inhibitors on Insulin Resistance and $\beta$-Cell Function in Type 2 Diabetes Mellitus: A Propensity Score-Matched Analysis
}

Jaehyun Bae - Gyuri Kim • Yong-Ho Lee - Byung-Wan Lee •

Eun Seok Kang · Bong-Soo Cha (D)

Received: September 7, 2018 / Published online: December 1, 2018

(c) The Author(s) 2018

\section{ABSTRACT}

Introduction: Comparisons of the glycemic durability between thiazolidinediones (TZDs) and dipeptidyl peptidase-4 (DPP-4) inhibitors remain insufficient. This study aimed to find clues for the differences in glycemic durability between TZDs and DPP-4 inhibitors by comparing the insulin resistance and $\beta$-cell function among patients using these agents.

Methods: A total of 241 patients with type 2 diabetes mellitus (T2DM) treated with either

Enhanced Digital Features To view enhanced digital features for this article go to https://doi.org/10.6084/ m9.figshare.7339367.

Electronic Supplementary Material The online version of this article (https://doi.org/10.1007/s13300018-0541-y) contains supplementary material, which is available to authorized users.

J. Bae · G. Kim · Y.-H. Lee · B.-W. Lee ·

E. S. Kang · B.-S. Cha $(\bowtie)$

Division of Endocrinology and Metabolism,

Department of Internal Medicine, Yonsei University

College of Medicine, Seoul, Republic of Korea

e-mail: BSCHA@yuhs.ac

\section{Present Address:}

G. Kim

Division of Endocrinology and Metabolism,

Department of Medicine, Samsung Medical Center,

Sungkyunkwan University School of Medicine,

Seoul, Republic of Korea pioglitazone (a TZD) or DPP-4 inhibitors as combination therapy with metformin for at least 1 year were analyzed. A propensity score based on the patients' baseline characteristics and glycated hemoglobin (HbA1c) was used to match them. Indices for insulin resistance and secretory function of $\beta$-cells, namely the homeostasis model assessment of insulin resistance (HOMA-IR) or $\beta$-cells (HOMA- $\beta$ ), were calculated and compared. Multiple regression analysis was performed to find the independent variables correlated with $\beta$-cell function or insulin resistance.

Results: Evaluation of the data from 168 matched patients with T2DM showed that TZD users had significantly better insulin sensitivity compared with DPP-4 inhibitor users (HOMA-IR $2.3 \pm 1.9$ vs. $3.5 \pm 3.2, p=0.003$ ). Conversely, DPP-4 inhibitor users secreted more insulin than TZD users (HOMA- $\beta \quad 45.7 \pm 31.6$ vs. $61.4 \pm 49.5, p=0.016)$. Multiple linear regression analysis showed that these agents were independently associated with both insulin resistance and $\beta$-cell function.

Conclusion: TZD users showed significantly better insulin sensitivity, whereas DPP-4 inhibitor users secreted more insulin from $\beta$-cells under similar glycemic control.

Keywords: Antidiabetic agents; $\quad \beta$-Cell function; Dipeptidyl-peptidase 4 inhibitors; Insulin resistance; Thiazolidinedione 


\section{INTRODUCTION}

Type 2 diabetes mellitus (T2DM) is a chronic metabolic disease characterized by progressive deterioration of insulin sensitivity and $\beta$-cell function [1]. Currently, there is no way to block the worsening of $\beta$-cell function completely; however, antidiabetic agents (ADAs) can partially slow down the progression of $\beta$-cell failure, with varying effects according to their mechanisms of action [2].

The A Diabetes Outcome Progression Trial (ADOPT) compared the monotherapy failure rates of three ADAs, namely metformin, glyburide, and rosiglitazone, and concluded that rosiglitazone had the most durable glycemic control effects [3]. A German study published in the same year as ADOPT revealed that pioglitazone added to metformin monotherapy afforded better long-term (3.5-year) glycemic control compared with the glibenclamide-added group [4]. These studies highlight the importance of improving insulin resistance because thiazolidinediones (TZDs), which primarily focus on insulin sensitivity, have a comparatively superior effect in slowing down the process of $\beta$-cell failure, as compared with other classes of ADAs. This is particularly important for patients with T2DM in East Asia such as Korea, whose $\beta$-cell function is often reduced at the time of diagnosis [5].

TZDs improve insulin resistance by activating peroxisome proliferator-activated receptor $\gamma$ $(\operatorname{PPAR} \gamma)$ [6], especially in adipose and liver tissue [7]. They are the only class of ADAs which primarily target insulin sensitivity, the core mechanism of T2DM. However, because of some safety issues such as fulminant hepatitis [8] and myocardial infarction [9], pioglitazone has become virtually the only TZD used around the world and has a relatively small portion of the current ADA market.

Dipeptidyl peptidase-4 (DPP-4) inhibitors are a class of ADAs that increase the active level of incretin, which enhances the secretion of insulin, while suppressing pancreatic glucagon secretion [10]. Because DPP-4 inhibitors have a potent hypoglycemic efficacy as well as a low risk of side effects, they are frequently prescribed by clinicians worldwide.

As a result of their mechanism, DPP-4 inhibitors are commonly believed to have a favorable effect on the secretory function of $\beta$-cells. However, their effect on insulin sensitivity remains controversial. In addition, studies comparing the glycemic durability of DPP-4 inhibitors with other ADAs, especially with TZDs, one of the most durable ADAs, are currently insufficient, although there were some randomized controlled trials comparing glycemic efficacy between TZDs and DPP-4 inhibitors [11-13]. In terms of glycemic efficacy, previous studies including the randomized controlled trials have shown that DPP-4 inhibitors were similar to or better than TZDs. However, a retrospective cohort study published in 2016 analyzed the glycemic durability among three ADA classes, namely sulfonylureas, TZDs, and DPP-4 inhibitors, as second-line treatment with metformin, and concluded that TZDs were the most durable agents, while DPP-4 inhibitors resulted in relatively poor durability [14].

Hence, in the current study, we sought to find clues for the differences in glycemic durability between TZDs and DPP-4 inhibitors by comparing the insulin resistance and $\beta$-cell function of patients with T2DM with good glycemic control status.

\section{METHODS}

\section{Patients and Data Collection}

We conducted a retrospective cross-sectional observational study on patients who visited the diabetes center at Severance Hospital in Seoul, South Korea during a 4-week period, from July 28 to August 21, 2014. A total of 241 patients with T2DM who were treated with either TZDs or DPP-4 inhibitors in combination with metformin for at least 1 year, regardless of other ADAs, were included. Insulin users and patients who were taking both TZDs and DPP-4 inhibitors were excluded.

The study protocol received ethical approval from the institutional review board at the 
Yonsei University College of Medicine (4-20180699), and adhered to the tenets of the 1964 Helsinki declaration and its later amendments or comparable ethical standards. Written informed consent was not required in this study because the database was only retrospectively accessed for analytic purposes and personal information was not used.

\section{Measurements of Clinical and Laboratory Parameters}

Demographic data such as age, sex, body mass index (BMI; $\mathrm{kg} / \mathrm{m}^{2}$ ), and duration of diabetes were retrospectively collected using electronic medical records. The duration of diabetes was defined from the date the patients were first diagnosed by blood tests or from the first visit to our clinic. Laboratory data, including serum glucose, c-peptide, insulin, and glycated hemoglobin (HbA1c), were acquired on the day of the visit. The serum glucose was measured by the standard glucose oxidase method using a 747 automatic analyzer (Hitachi, Tokyo, Japan), and the HbA1c was checked by high-performance liquid chromatography (Variant II; Bio-Rad, Hercules, CA, USA). The serum insulin and c-peptide levels were measured in duplicate by immunoradiometric assay (Beckman Coulter, Fullerton, CA, USA).

\section{Study Outcomes (Endpoints)}

The primary outcomes of the present study were the insulin resistance and $\beta$-cell function of patients with T2DM treated with TZDs vs. DPP4 inhibitors, as determined by the homeostasis model assessment (HOMA), calculated using the following formulas [15]:

HOMA-IR $=($ fasting insulin $[\mu \mathrm{U} / \mathrm{ml}] \times$ fasting blood glucose $[\mathrm{mg} / \mathrm{dl}]) / 405$

HOMA $-\beta=(360 \times$ fasting insulin $[\mu \mathrm{U} / \mathrm{ml}]) /$ (Fasting blood glucose $[\mathrm{mg} / \mathrm{dl}]-63$ )

\section{Statistical Analysis}

The $\beta$-cell function and insulin resistance of patients with T2DM were compared according to their ADAs (TZD or DPP-4 inhibitor).
Student's $t$ test and the $\chi^{2}$ test were used to compare continuous and categorical variables between the two groups. To minimize the influence of demographic characteristics and to compare the variables in patients under similar glycemic control, we used propensity score matching based on the patients' baseline characteristics and HbA1c level.

To find the independent variables significantly correlated with $\beta$-cell function or insulin resistance, we also performed simple correlation analysis and multiple regression analysis.

Continuous variables are expressed as mean \pm standard deviation (SD), and categorical variables as numbers and percentages (\%).

\section{RESULTS}

\section{Study Population Characteristics}

A total of 241 patients with T2DM who were treated with either TZDs or DPP-4 inhibitors in combination with metformin for at least 1 year were included in the present study (Fig. 1). Pioglitazone was the only TZD prescribed in this study, and three kinds of DPP-4 inhibitors, namely sitagliptin, vildagliptin, and linagliptin, were used. There were 109 patients taking sulfonylureas as triple therapy, accounting for about $45 \%$ of patients in each group [60 (46.2\%) in the TZD group vs. $49(44.1 \%)$ in the DPP-4 inhibitor group, $p=0.755]$. The two treatment groups had different baseline characteristics, including sex and duration of diabetes (Table S1; see Supplementary Material associated with this article online). Specifically, the TZD group had a higher percentage of male patients and longer duration of diabetes compared with the DPP-4 inhibitor group.

After 1:1 propensity score matching, 84 pairs of patients remained in this study (Table 1). There were no significant differences in demographic variables and HbA1c between the TZD and DPP-4 inhibitor groups. The mean age of the patients was 62.2 years in the TZD group and 62.5 years in the DPP-4 inhibitor group. In both groups, the patients tended to be overweight [mean BMI $25.6 \pm 3.4$ (TZD group) vs. $25.9 \pm 3.3$ (DPP-4 inhibitor group), $p=0.553$ ] 


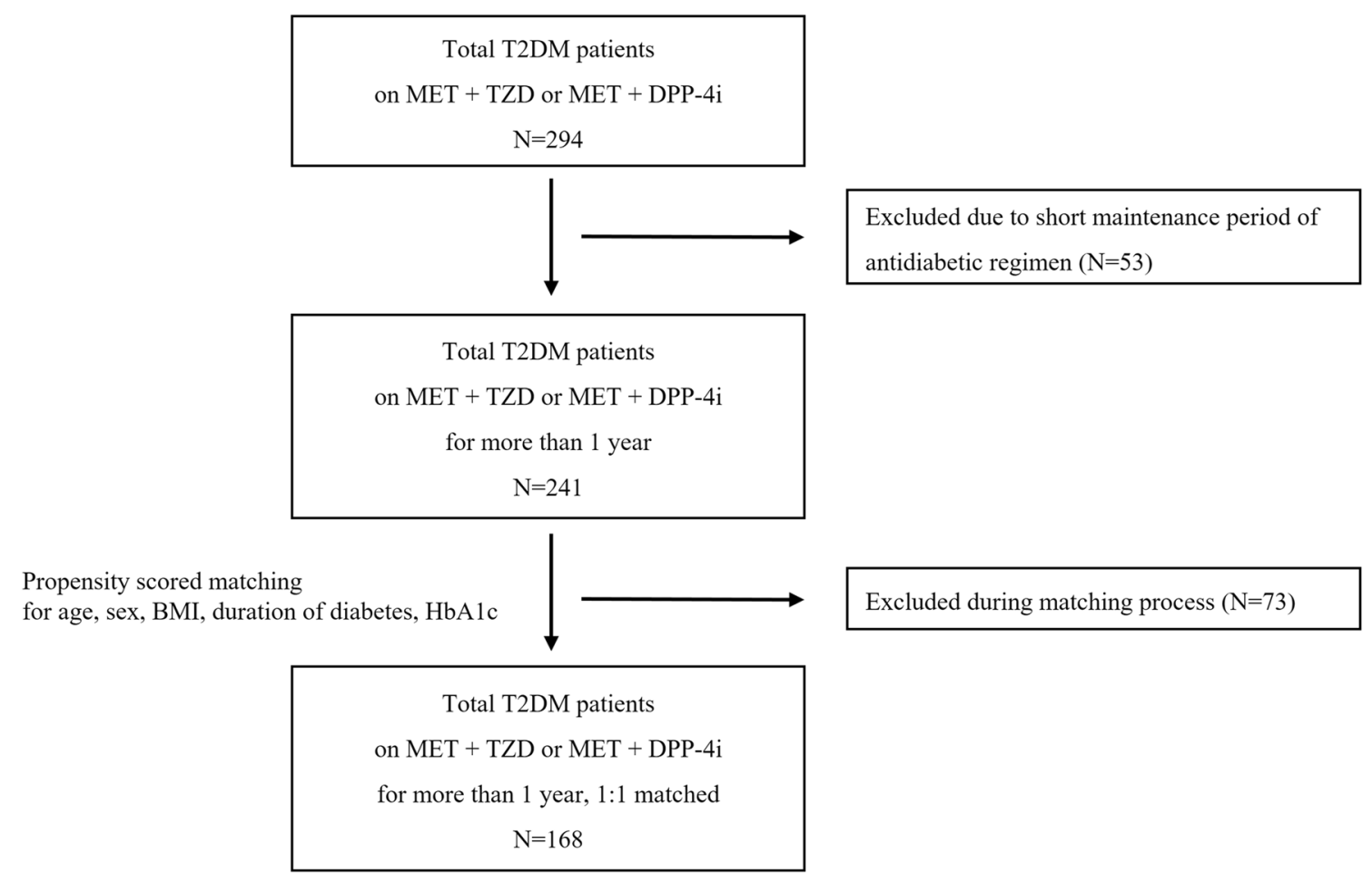

Fig. 1 Schematic diagram for the study design. T2DM type 2 diabetes mellitus, MET metformin, TZD thiazolidinedione, DPP-4i dipeptidyl peptidase 4 inhibitors, BMI body mass index, HbAlc glycated hemoglobin

and to have a long duration of diabetes $(11.5 \pm 5.9$ vs. $11.2 \pm 6.9$ years, $p=0.772)$. The mean $\mathrm{HbA1c}$ of both groups was $6.8 \%$ $(51 \mathrm{mmol} / \mathrm{mol})$, which is close to the glycemic goal $(6.8 \pm 0.8 \%, \quad 51.0 \pm 8.8 \mathrm{mmol} / \mathrm{mol}$ vs. $6.8 \pm 0.7 \%, 51.2 \pm 8.1 \mathrm{mmol} / \mathrm{mol}, p=0.873)$.

\section{Insulin Resistance and $\beta$-Cell Function of the Two Groups in the Propensity Score- Matched Sample}

Under the same degree of glycemic control, the c-peptide and insulin levels of the TZD group were lower than those in the DPP-4 inhibitor group. The fasting c-peptide, postprandial c-peptide, fasting insulin, and postprandial insulin levels were $2.1 \pm 0.8,6.1 \pm 2.3$, $7.1 \pm 4.8$, and $34.9 \pm 25.6 \mu \mathrm{U} / \mathrm{mL}$ in the TZD group and $2.7 \pm 1.3,7.2 \pm 3.2,10.4 \pm 8.4$, and $46.7 \pm 34.4 \mu \mathrm{U} / \mathrm{mL}$ in the DPP-4 inhibitor group, respectively. When we measured the insulin resistance by calculating the HOMA-IR, the TZD group showed significantly better insulin sensitivity $(2.3 \pm 1.9$ vs. $3.5 \pm 3.2$, $p=0.003$ ) (Table 1, Fig. 2). On the other hand, the HOMA- $\beta$, an index for the secretory function of $\beta$-cells, was markedly higher in the DPP4 inhibitor group compared with in the TZD group $(45.7 \pm 31.6$ vs. $61.4 \pm 49.5, p=0.016)$ (Table 1, Fig. 3).

\section{Independent Variables Correlated with $\beta$ - Cell Function or Insulin Sensitivity}

In the simple correlation analysis, TZD was found to be negatively correlated with HOMAIR, while DPP- 4 inhibitors positively correlated with HOMA- $\beta$. In addition, BMI and HbA1c positively correlated with HOMA-IR, whereas the HbA1c level and duration of diabetes negatively correlated with HOMA- $\beta$ (Table 2 ).

In the multiple regression analysis, HOMAIR was found to be independently associated with ADAs $(\beta=1.14, p=0.003)$, with TZD use being independently associated with better insulin sensitivity. Conversely, higher BMI and 
Table 1 Demographic and metabolic variables of both groups after matching with propensity scores

\begin{tabular}{|c|c|c|c|}
\hline & TZD & DPP-4i & $p$ value \\
\hline$n$ & 84 & 84 & \\
\hline Age (years) & $62.2 \pm 9.9$ & $62.5 \pm 10.6$ & 0.863 \\
\hline $\operatorname{Men}(n, \%)$ & $47(56.0)$ & $49(58.3)$ & 0.755 \\
\hline $\operatorname{BMI}\left(\mathrm{kg} / \mathrm{m}^{2}\right)$ & $25.6 \pm 3.4$ & $25.9 \pm 3.3$ & 0.553 \\
\hline Duration of diabetes (years) & $11.5 \pm 5.9$ & $11.2 \pm 6.9$ & 0.772 \\
\hline Fasting serum glucose $(\mathrm{mg} / \mathrm{dL})$ & $126.4 \pm 27.0$ & $132.4 \pm 28.9$ & 0.165 \\
\hline Postprandial serum glucose $(\mathrm{mg} / \mathrm{dL})$ & $186.0 \pm 65.3$ & $209.7 \pm 66.4$ & 0.024 \\
\hline Fasting insulin $(\mu \mathrm{U} / \mathrm{mL})$ & $7.1 \pm 4.8$ & $10.4 \pm 8.4$ & 0.002 \\
\hline Postprandial insulin $(\mu \mathrm{U} / \mathrm{mL})$ & $34.9 \pm 25.6$ & $46.7 \pm 34.4$ & 0.013 \\
\hline Fasting c-peptide $(\mu \mathrm{U} / \mathrm{mL})$ & $2.1 \pm 0.8$ & $2.7 \pm 1.3$ & $<0.001$ \\
\hline Postprandial c-peptide $(\mu \mathrm{U} / \mathrm{mL})$ & $6.1 \pm 2.3$ & $7.2 \pm 3.2$ & 0.007 \\
\hline HbAlc (\%) & $6.8 \pm 0.8$ & $6.8 \pm 0.7$ & 0.873 \\
\hline HOMA-IR & $2.3 \pm 1.9$ & $3.5 \pm 3.2$ & 0.003 \\
\hline HOMA- $\beta$ & $45.7 \pm 31.6$ & $61.4 \pm 49.5$ & 0.016 \\
\hline \multicolumn{4}{|l|}{ Concomitant ADAs $(n, \%)$} \\
\hline Sulfonylurea & $31(36.9)$ & $38(45.2)$ & 0.272 \\
\hline
\end{tabular}

Data are expressed as mean \pm SD

$T Z D$ thiazolidinedione, $D P P-4 i$ dipeptidyl peptidase 4 inhibitors, $B M I$ body mass index, $H b A l c$ glycated hemoglobin, $H O M A-I R$ homeostasis model assessment of insulin resistance, $H O M A-\beta$ homeostasis model assessment of $\beta$-cells, $A D A s$ antidiabetic agents

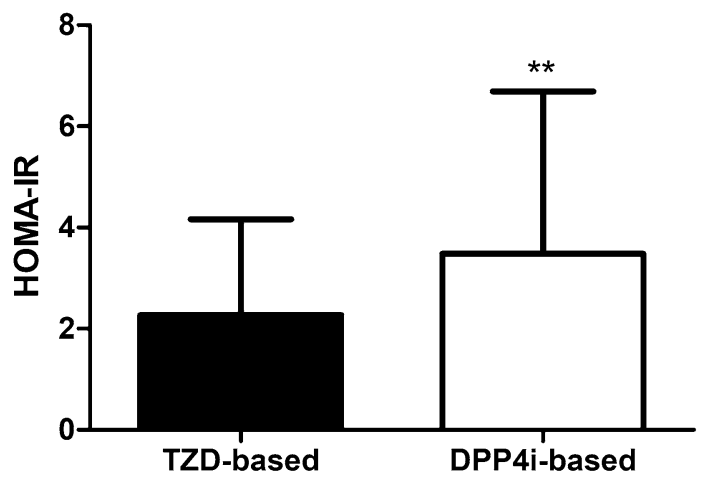

Fig. 2 Differences of insulin resistance between two groups after matching with propensity score. TZD thiazolidinedione, DPP-4i dipeptidyl peptidase 4 inhibitors

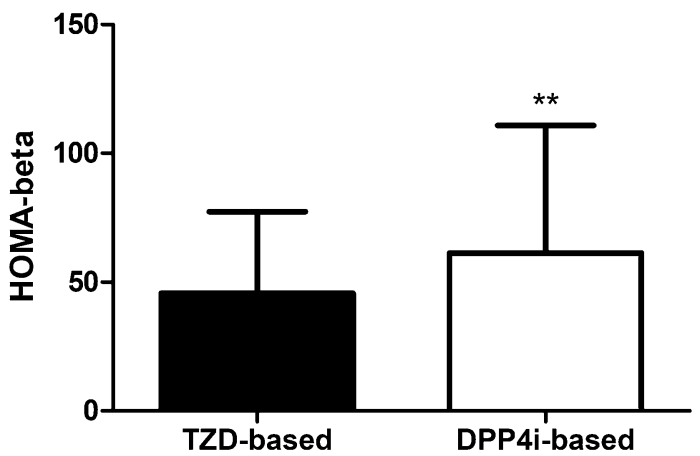

Fig. 3 Differences of $\beta$-cell function between two groups after matching with propensity score. TZD thiazolidinedione, DPP-4i dipeptidyl peptidase 4 inhibitors 
Table 2 Simple correlation analysis to find factors correlated to HOMA-IR or HOMA- $\beta$

\begin{tabular}{|c|c|c|c|c|}
\hline & \multicolumn{2}{|c|}{ HOMA-IR } & \multicolumn{2}{|c|}{ HOMA- $\beta$} \\
\hline & $r$ & $p$ value & $r$ & $p$ value \\
\hline Age (years) & -0.11 & 0.172 & -0.15 & 0.056 \\
\hline Gender & 0.03 & 0.683 & 0.12 & 0.138 \\
\hline $\operatorname{BMI}\left(\mathrm{kg} / \mathrm{m}^{2}\right)$ & 0.33 & $<0.001$ & 0.39 & $<0.001$ \\
\hline Duration of diabetes (years) & -0.04 & 0.588 & -0.23 & 0.003 \\
\hline HbA1c $(\%)$ & 0.32 & $<0.001$ & -0.16 & 0.038 \\
\hline ADAs; TZD-based (0) or DPP-4i-based (1) & 0.30 & $<0.001$ & 0.18 & 0.019 \\
\hline SU co-medication & 0.08 & 0.286 & -0.13 & 0.087 \\
\hline
\end{tabular}

HOMA-IR homeostasis model assessment of insulin resistance, HOMA- $\beta$ homeostasis model assessment of $\beta$-cells, $r$ correlation coefficient, $B M I$ body mass index, $H b A l c$ glycated hemoglobin, $A D A s$ antidiabetic agents, TZD thiazolidinedione, $D P P-4 i$ dipeptidyl peptidase 4 inhibitors, $S U$ sulfonylurea

Table 3 Multivariate regression analysis of factors associated with insulin resistance and $\beta$-cell function

\begin{tabular}{|c|c|c|c|c|}
\hline & \multicolumn{2}{|c|}{ HOMA-IR } & \multicolumn{2}{|c|}{ НОМА- $\beta$} \\
\hline & $\bar{\beta}$ & $p$ value & $\bar{\beta}$ & $p$ value \\
\hline Age & -0.02 & 0.468 & -0.24 & 0.469 \\
\hline Gender: male $(0)$ or female $(1)$ & 0.12 & 0.762 & 3.89 & 0.527 \\
\hline $\operatorname{BMI}\left(\mathrm{kg} / \mathrm{m}^{2}\right)$ & 0.25 & $<0.001$ & 4.29 & $<0.001$ \\
\hline Duration of diabetes (years) & -0.02 & 0.599 & -0.83 & 0.147 \\
\hline HbAlc & 1.12 & $<0.001$ & -7.36 & 0.085 \\
\hline ADAs: TZD-based (0) or DPP-4i-based (1) & 1.14 & 0.003 & 13.70 & 0.024 \\
\hline SU co-medication: no $(0)$ or yes $(1)$ & 0.17 & 0.712 & 1.61 & 0.823 \\
\hline
\end{tabular}

HOMA-IR homeostasis model assessment of insulin resistance, $H O M A-\beta$ homeostasis model assessment of $\beta$-cells, $\beta$ regression coefficient, $B M I$ body mass index, $H b A 1 c$ glycated hemoglobin, $A D A s$ antidiabetic agents, TZD thiazolidinedione, $D P P-4 i$ dipeptidyl peptidase 4 inhibitors, $S U$ sulfonylurea

HbA1c were independently associated with worse insulin resistance $(\beta=0.25$ and 1.12, respectively, $p<0.001$ ) (Table 3 ).

In addition, DPP-4 inhibitors and higher BMI were shown to be independent factors associated with higher $\beta$-cell secretory function $(\beta=13.70$ and 4.29, $p=0.024$ and $<0.001$, respectively) (Table 3 ).

\section{DISCUSSION}

In the present propensity score-matched analysis, we compared the insulin resistance and $\beta$ cell function of TZD and DPP-4 inhibitor users. The study sample comprised patients with T2DM who were taking TZD or DPP-4 inhibitors as combination therapy with metformin for at least 1 year. Although the duration of T2DM 
ranged from 1 to 39 years, the overall duration tended to be long (mean duration $11.3 \pm 6.4$ years), and most patients were under adequate glycemic control (mean HbA1c $6.8 \pm 0.8,51 \mathrm{mmol} / \mathrm{mol}$ ). To minimize the effects of different demographic characteristics and to compare the variables in patients under similar glycemic control, propensity score matching was performed.

Under similar glycemic control and demographic factors, DPP-4 inhibitor users showed higher serum insulin, c-peptide levels, and HOMA- $\beta$, while TZD users had lower HOMA-IR and HOMA- $\beta$. These findings reflect a situation in which there is no need to secrete plenty of insulin, owing to the lower insulin resistance in TZD users. Regression analysis confirmed that TZDs and DPP-4 inhibitors were independent variables associated with insulin resistance and $\beta$-cell function.

As T2DM usually progresses and finally leads to $\beta$-cell failure, studies on the glycemic durability of ADAs have attracted the interest of clinicians and researchers for a long time. Comparing the glycemic durability of ADAs, however, is not easy, because it requires a sufficient number of controlled samples and longterm follow-up data. Hence, there are currently not enough well-organized, large-scale, population-based studies on the durability of various ADAs.

TZDs, which are insulin sensitizers, have been consistently demonstrated to have excellent glycemic durability in numerous studies. ADOPT reported that rosiglitazone showed superior glycemic durability as monotherapy for T2DM compared with metformin and glyburide [3]. As combination therapy with metformin, pioglitazone also showed excellent glycemic durability when compared with sulfonylurea alone $[4,16]$, or with a sulfonylurea and DPP-4 inhibitor [14]. These results suggest that improvement of insulin resistance might be more beneficial for maintaining glycemic durability in terms of alleviating $\beta$-cell workloads.

The effect of DPP-4 inhibitors on insulin resistance has been studied in several research studies, but it was still controversial. Several studies have shown that addition of DPP-4 inhibitor to the previous regimen or metformin lowered insulin resistance $[17,18]$. In contrast, in some other studies, the addition of DPP-4 inhibitors significantly lowered blood glucose, but insulin resistance was not improved compared with placebo or other ADA $[19,20]$. In the present study, it was still not clear whether DPP4 inhibitors ameliorate insulin sensitivity, but their influence on insulin resistance was not as effective as TZDs.

Although the effect of DPP-4 inhibitors on insulin sensitivity is not fully elucidated, they are expected to provide relatively long-term sustainable glycemic control, since their mechanism is considered to be more favorable than that of sulfonylureas. In fact, some studies have demonstrated results in line with this expectation. In a multinational, randomized, non-inferiority study reported in 2010, the addition of sitagliptin to metformin resulted in similar reduction of HbA1c after 2 years of treatment, but favorable outcomes in terms of glycemic durability, such as the slope of change in HbA1c over time and $\beta$-cell function after a washout period, compared with the addition of glipizide [21]. Italian researchers reported that sitagliptin as combination therapy provided a better HbA1c-lowering efficacy after 5 years of treatment, compared with sulfonylureas, pioglitazone, and metformin [22]. However, as mentioned above, a retrospective cohort study published in 2016 revealed worse glycemic durability of DPP-4 inhibitors compared with sulfonylureas and TZDs [14].

Some researchers have reported that incretin-based ADAs such as DPP-4 inhibitors and glucagon-like peptide 1 agonists stimulate $\beta$-cell survival and preserve their mass and function in animal models [23-25] and human studies [26], supporting the long-term effectiveness of DPP-4 inhibitors for glycemic control, apart from improvement of insulin sensitivity. For now, though, there is little evidence in humans to support durable disease-modifying effects of DPP-4 inhibitors on $\beta$-cell mass or function $[27,28]$. Unsustainable effects of DPP-4 inhibitors on $\beta$-cell function after drug washout have been reported in previous research [29-31], and these are in line with this notion.

Therefore, on the basis of the current state of knowledge, improvement in insulin resistance 
is one of the most important and reasonable methods for glycemic durability, because no current ADA was proven to restore the mass or survival of $\beta$-cells themselves, in the long term. In the present study, TZD use was associated with significantly improved insulin resistance compared with DPP-4 inhibitor use in patients with T2DM under similar glycemic control. These results suggest that TZDs might be in a more advantageous position for glycemic durability than DPP-4 inhibitors, in terms of insulin resistance, in line with a previous retrospective cohort study [14]. However, we should not underestimate the effects of DPP-4 inhibitors, improvement of the $\beta$-cell function, as unsustainable effects. Long-term effects of DPP-4 inhibitors on $\beta$-cells are not sufficiently evaluated, and well-designed, longitudinal studies are needed. In addition, the effect of DPP-4 inhibitors on $\beta$-cells and TZDs' insulin sensitizing effect might be mutually complementary, suggesting that combination therapy would be significantly effective. There were several studies in line with this notion [32-34].

Our study has some limitations. The size of sample was relatively small, and the design was a cross-sectional study. Therefore, we could not describe conclusively the glycemic durability of two ADAs, and this study showed us simply a clue about it. For more critical evidence about glycemic durability, well-designed, longitudinal, prospective studies are needed. Information about the lifestyle of the patients, including diet and exercise, and other medications for comorbidities were not surveyed, so we could not match for these factors before comparison. However, we minimized the interference of other demographic characteristics by using propensity score matching. This study can be considered meaningful because, to our knowledge, it is the first study to compare the insulin resistance and $\beta$-cell function of TZD- and DPP4 inhibitor-treated patients with T2DM with similar glycemic control.

\section{CONCLUSIONS}

Under similar glycemic status, TZD users showed more improved insulin resistance, whereas DPP-4 inhibitor users secreted more insulin from their $\beta$-cells. Well-designed, largescale, prospective studies are needed to clarify the effect of DPP-4 inhibitors on insulin resistance and $\beta$-cell function.

\section{ACKNOWLEDGEMENTS}

Funding. No funding or sponsorship was received for this study or publication of this article. The article processing charges were funded by the authors.

Authorship. All named authors meet the International Committee of Medical Journal Editors (ICMJE) criteria for authorship for this article, take responsibility for the integrity of the work as a whole, and have given their approval for this version to be published.

Authorship Contributions. Jaehyun Bae and Bong-Soo Cha designed the study. Jaehyun Bae analyzed and interpreted the date and wrote the manuscript. Gyuri Kim, Yong-ho Lee, ByungWan Lee and Eun Seok Kang contributed to the data analysis. Yong-Ho Lee contributed to the revision of manuscript. All authors contributed to the interpretation of results, critical revision of the manuscript and approved the final manuscript. Bong-Soo Cha is the guarantor.

Disclosures. Jaehyun Bae, Gyuri Kim, YongHo Lee, Byung-Wan Lee, Eun Seok Kang, BongSoo Cha declare that they have no conflict of interest.

Compliance with Ethics Guidelines. All analyses performed in this study were based on retrospective medical chart review, within the ethical standards.

The study protocol received ethical approval from the institutional review board at the Yonsei University College of Medicine (4-20180699), and adhered to the tenets of the Declaration of Helsinki and its later amendments or comparable ethical standards. 
Data Availability. The datasets generated during and/or analyzed during the current study are available from the corresponding author on reasonable request.

Open Access. This article is distributed under the terms of the Creative Commons Attribution-NonCommercial 4.0 International License (http://creativecommons.org/licenses/ by-nc/4.0/), which permits any noncommercial use, distribution, and reproduction in any medium, provided you give appropriate credit to the original author(s) and the source, provide a link to the Creative Commons license, and indicate if changes were made.

\section{REFERENCES}

1. Kahn SE. The relative contributions of insulin resistance and beta-cell dysfunction to the pathophysiology of type 2 diabetes. Diabetologia. 2003;46:3-19.

2. Samtani MN. Simple pharmacometric tools for oral anti-diabetic drug development: competitive landscape for oral non-insulin therapies in type 2 diabetes. Biopharm Drug Dispos. 2010;31:162-77.

3. Kahn SE, Haffner SM, Heise MA, et al. Glycemic durability of rosiglitazone, metformin, or glyburide monotherapy. N Engl J Med. 2006;355:2427-43.

4. Hanefeld M, Pfutzner A, Forst T, Lubben G. Glycemic control and treatment failure with pioglitazone versus glibenclamide in type 2 diabetes mellitus: a 42-month, open-label, observational, primary care study. Curr Med Res Opin. 2006;22:1211-5.

5. Kim DJ, Lee MS, Kim KW, Lee MK. Insulin secretory dysfunction and insulin resistance in the pathogenesis of Korean type 2 diabetes mellitus. Metabolism. 2001;50:590-3.

6. Lehmann JM, Moore LB, Smith-Oliver TA, Wilkison WO, Willson TM, Kliewer SA. An antidiabetic thiazolidinedione is a high affinity ligand for peroxisome proliferator-activated receptor gamma (PPAR gamma). J Biol Chem. 1995;270:12953-6.

7. Rizos CV, Liberopoulos EN, Mikhailidis DP, Elisaf MS. Pleiotropic effects of thiazolidinediones. Expert Opin Pharmacother. 2008;9:1087-108.
8. Kohlroser J, Mathai J, Reichheld J, Banner BF, Bonkovsky HL. Hepatotoxicity due to troglitazone: report of two cases and review of adverse events reported to the United States Food and Drug Administration. Am J Gastroenterol. 2000;95:272-6.

9. Nissen SE, Wolski K. Effect of rosiglitazone on the risk of myocardial infarction and death from cardiovascular causes. $\mathrm{N}$ Engl J Med. 2007;356:2457-71.

10. Barnett A. DPP-4 inhibitors and their potential role in the management of type 2 diabetes. Int J Clin Pract. 2006;60:1454-70.

11. Liu SC, Chien KL, Wang $\mathrm{CH}$, Chen WC, Leung $\mathrm{CH}$. Efficacy and safety of adding pioglitazone or sitagliptin to patients with type 2 diabetes insufficiently controlled with metformin and a sulfonylurea. Endocr Pract. 2013;19:980-8.

12. Takihata $M$, Nakamura A, Tajima $K$, et al. Comparative study of sitagliptin with pioglitazone in Japanese type 2 diabetic patients: the COMPASS randomized controlled trial. Diabetes Obes Metab. 2013;15:455-62.

13. Chawla S, Kaushik N, Singh NP, Ghosh RK, Saxena A. Effect of addition of either sitagliptin or pioglitazone in patients with uncontrolled type 2 diabetes mellitus on metformin: a randomized controlled trial. J Pharmacol Pharmacother. 2013;4:27-32.

14. Mamza J, Mehta R, Donnelly R, Idris I. Important differences in the durability of glycaemic response among second-line treatment options when added to metformin in type 2 diabetes: a retrospective cohort study. Ann Med. 2016;48:224-34.

15. Wallace TM, Levy JC, Matthews DR. Use and abuse of HOMA modeling. Diabetes Care. 2004;27:1487-95.

16. Charbonnel B, Schernthaner G, Brunetti P, et al. Long-term efficacy and tolerability of add-on pioglitazone therapy to failing monotherapy compared with addition of gliclazide or metformin in patients with type 2 diabetes. Diabetologia. 2005;48:1093-104.

17. Derosa G, Ragonesi PD, Fogari E, et al. Sitagliptin added to previously taken antidiabetic agents on insulin resistance and lipid profile: a 2-year study evaluation. Fundam Clin Pharmacol. 2014;28:221-9.

18. Strozik A, Steposz A, Basiak M, Drozdz M, Okopien B. Multifactorial effects of vildagliptin added to ongoing metformin therapy in patients with type 2 diabetes mellitus. Pharmacol Rep. 2015;67:24-31. 
19. Goldstein BJ, Feinglos MN, Lunceford JK, Johnson J, Williams-Herman DE, Sitagliptin 036 Study Group. Effect of initial combination therapy with sitagliptin, a dipeptidyl peptidase- 4 inhibitor, and metformin on glycemic control in patients with type 2 diabetes. Diabetes Care. 2007;30: 1979-87.

20. Taskinen MR, Rosenstock J, Tamminen I, et al. Safety and efficacy of linagliptin as add-on therapy to metformin in patients with type 2 diabetes: a randomized, double-blind, placebo-controlled study. Diabetes Obes Metab. 2011;13:65-74.

21. Seck T, Nauck M, Sheng D, et al. Safety and efficacy of treatment with sitagliptin or glipizide in patients with type 2 diabetes inadequately controlled on metformin: a 2-year study. Int J Clin Pract. 2010;64:562-76.

22. Derosa G, D'Angelo A, Maffioli P. Sitagliptin in type 2 diabetes mellitus: efficacy after five years of therapy. Pharmacol Res. 2015;100:127-34.

23. Farilla L, Hui H, Bertolotto C, et al. Glucagon-like peptide-1 promotes islet cell growth and inhibits apoptosis in Zucker diabetic rats. Endocrinology. 2002;143:4397-408.

24. Mu J, Woods J, Zhou YP, et al. Chronic inhibition of dipeptidyl peptidase- 4 with a sitagliptin analog preserves pancreatic beta-cell mass and function in a rodent model of type 2 diabetes. Diabetes. 2006;55:1695-704.

25. Pospisilik JA, Martin J, Doty T, et al. Dipeptidyl peptidase IV inhibitor treatment stimulates betacell survival and islet neogenesis in streptozotocininduced diabetic rats. Diabetes. 2003;52:741-50.

26. Shah P, Ardestani A, Dharmadhikari G, et al. The DPP-4 inhibitor linagliptin restores beta-cell function and survival in human isolated islets through GLP-1 stabilization. J Clin Endocrinol Metab. 2013;98:E1163-72.
27. Lyu X, Zhu X, Zhao B, et al. Effects of dipeptidyl peptidase- 4 inhibitors on beta-cell function and insulin resistance in type 2 diabetes: meta-analysis of randomized controlled trials. Sci Rep. 2017;7:44865.

28. van Genugten RE, van Raalte $\mathrm{DH}$, Diamant $\mathrm{M}$. Dipeptidyl peptidase- 4 inhibitors and preservation of pancreatic islet-cell function: a critical appraisal of the evidence. Diabetes Obes Metab. 2012;14:101-11.

29. D'Alessio DA, Denney AM, Hermiller LM, et al. Treatment with the dipeptidyl peptidase- 4 inhibitor vildagliptin improves fasting islet-cell function in subjects with type 2 diabetes. J Clin Endocrinol Metab. 2009;94:81-8.

30. Foley JE, Bunck MC, Moller-Goede DL, et al. Beta cell function following 1 year vildagliptin or placebo treatment and after 12 week washout in drugnaive patients with type 2 diabetes and mild hyperglycaemia: a randomised controlled trial. Diabetologia. 2011;54:1985-91.

31. Scherbaum WA, Schweizer A, Mari A, et al. Efficacy and tolerability of vildagliptin in drug-naive patients with type 2 diabetes and mild hyperglycaemia. Diabetes Obes Metab. 2008;10:675-82.

32. Alba M, Ahren B, Inzucchi SE, et al. Sitagliptin and pioglitazone provide complementary effects on postprandial glucose and pancreatic islet cell function. Diabetes Obes Metab. 2013;15:1101-10.

33. Suzuki A, Yoshimura N, Mashimo Y, et al. One-year real-life efficacy of sitagliptin revealed importance of concomitant pioglitazone use in Japanese patients with type 2 diabetes mellitus. Diabetes Metab Syndr. 2013;7:143-7.

34. Lee JY, Cho Y, Lee M, et al. Clinical efficacy of the novel thiazolidinedione lobeglitazone in patients with type 2 diabetes. Diabetes Metab. 2018;44:452-5. 